\title{
The Role of Priming with Biosynthesized Silver Nanoparticles in the Response of Triticum aestivum L. to Salt Stress
}

\author{
Hanan Mahmoud Abou-Zeid and Ghada Saber Mohamed Ismail ${ }^{\#}$ \\ Botany and Microbiology Department, Faculty of Science, Alexandria University, \\ Alexandria, Egypt.
}

\begin{abstract}
$\mathbf{T}$ HE PRESENT study investigated the synthesis of silver nanoparticles (AgNPs) using Capparis spinosa extract as reducing and stabilizing agent. The biosynthesized AgNPs were characterized by UV-vis spectrophotometer and energy dispersive spectroscopy (EDS) analysis. The shape and size of the biosynthesized AgNPs were studied using transmission electron microscope (TEM). The study also investigated whether the biosynthesized AgNPs (as a priming agent; $1 \mathrm{mg} \mathrm{L}^{-1}$ ) has a role in the alleviation of the salt-induced toxicity of germinating Triticum aestivum L. grains grown under salt stress $(25$ and $100 \mathrm{mM} \mathrm{NaCl}$ ). Generally, AgNPs priming stimulate the germination and growth of wheat grains. In addition, it affects the plant phytohormones balance by stimulating indole-3-butyric acid (IBA), 1-naphthalene acetic acid (NAA), 6-benzylaminopurine (BAP) contents and reducing abscicic acid (ABA) content. Slat stress had an inhibitory effect on wheat seedling as evident by a significant decrease in GP, growth index, pigment contents and chlorophyll stability index (CSI), auxins and cytokinins contents and a marked increase in ABA content particularly at $100 \mathrm{mM} \mathrm{NaCl}$. All these parameters were markedly improved by AgNPs priming notably growth parameters and photosynthetic efficiency as well phtyohormones balance suggesting that AgNPs priming might has a role in the improvement of plant tolerance against environmental stresses such as salinity.
\end{abstract}

Keywords: Green synthesis, Salinity, Silver nanoparticles, Priming, Wheat.

\section{Introduction}

Salinity is considered as one of the most threatening abiotic stresses affecting crop productivity leading to severe crop damage (Hussain et al., 2016). It affects the metabolism of plant cells and induces a number of secondary stresses including water deficit, oxidative damages and nutritional imbalance thereby impairing vital cellular functions (Morari et al., 2015).

Seed germination is one of the most sensitive processes to environmental factors because of the lack of some defense mechanisms and hence it is an important consideration while studying the effects of salinity on seedling growth. Salinity may affect germination and seedling growth through reduced osmotic potential, increased availability of toxic ions and disruption of photosynthetic machinery (Farooq et al., 2015).

It has been reported that seed priming is a beneficial technique to improve seed germination and could be an attractive approach to overcome growth retardation of young plants in the saltaffected soils (Chunthaburee et al., 2014). Priming allows some of the metabolic processes necessary for germination to proceed, before germination is completed (Ghobadi et al., 2012). Briefly, the performance of various crops could be improved by using various growth regulators as well as bionanoparticles as priming agents (Bhati-Kushwaha et al., 2013 and Abou-Zeid \& Moustafa, 2014). Nanoparticles have unique properties as a consequence of their size, distribution and morphology. Therefore, compared to bulk materials, they exhibit outstanding characteristics such as electrical, magnetic and optical properties (Sorescu et al., 2016). Among nanomaterials, silver nanoparticles (AgNPs) play an important role in the field of biology and medicine due to their attractive physiochemical properties (Benakashani et al., 2016). Various chemical and physical methods are known for preparation of silver and other metal nanoparticles. However,

"Corresponding author email: ghada5f@yahoo.com

DOI :10.21608/ejbo.2017.1873.1128

C2018 National Information and Documentation Center (NIDOC) 
the development of a reliable green process for the synthesis of AgNPs has gained importance in the current nanotechnology research since these bio-based protocols are simple, relatively inexpensive, environmentally friendly and easily scaled up for larger scale production (Bansal et al., 2015). Nowadays, the sustainability initiatives that use green chemistry to improve and/or protect our global environment are focal issues in many fields of research and AgNPs have been implicated in agriculture for improving crops. Vannini et al. (2013) had indicated that the impact of AgNPs on seed germination vary with nanoparticles characteristics and plant species. Many investigations showed more negative effects in plants exposed to AgNPs than bulk Ag such as Allium cepa and Cucurbita pepo (Kumar et al., 2009 and Musante \& White, 2012). However, other studies have demonstrated that AgNPs play an important role in enhancing seed germination and plant growth in different plant species such as Brassica juncea (Sharma et al., 2012), Helianthus annuus and Glycine max (Shelar \& Chavan, 2015). Furthermore, application of AgNPs has been found quite effective in improving resistance against salinity during germination of Foeniculum vulgare Mill (Ekhtiyari et al., 2011) and Solanum lycopersicum L. (Almutairi, 2015). Although the potential of AgNPs in improving salinity resistance has been reported in several plant species (Ekhtiyari \& Moraghebi, 2011), however its role in the alleviation of salinity effect and related mechanisms is still unknown.

Capparis spinosa is an evergreen shrub belonging to the family Capparaceae and was commonly used as a medicinal plant. It contained many biologically active chemical groups including, alkaloids, glycosides, tannins, phenolics, flavonoids, triterpenoids steroids, carbohydrates, saponins and a wide range of minerals and trace elements (Al-Snafi, 2015). Wheat (Triticum aestivum L.) is one of the most important cereal food crops in Egypt and according to FAO publications, Egypt is one of the heavy users of wheat but the imports of this crop exceed the production. However, to achieve sustainable increase in wheat production, new cheaper and efficient technologies have to be employed. Since nanotechnology might offer one of these technologies, the present study was undertaken to assess the effect of the biogenic AgNPs synthesized from Capparis spinosa on alleviation of the salt-induced toxicity of germinating Triticum aestivum L. grains. The changes in seed germination, seedling growth parameters, photosynthetic efficiency and hormonal content were followed.

\section{Materials and Methods}

Biosynthesis and characterization of AgNPs

Biosynthesis of AgNPs

Capparis spinosa L. dried plant were chopped and cut into small pieces and then grinded to the powdered form. The extract solution was prepared by boiling powdered plant material (10 g) in Erlenmeyer flask with $100 \mathrm{~mL}$ of deionized distilled water for ten minutes at $100^{\circ} \mathrm{C}$. The boiled suspensions were filtered through Whatman No 1 filter paper and the filtrate was collected and stored at $4^{\circ} \mathrm{C}$ for further use (Dwivedi \& Gopal, 2010). For preparation of AgNPs, $10 \mathrm{~mL}$ of the prepared extract was typically added to $100 \mathrm{~mL}$ of $3 \mathrm{mM}$ aqueous silver nitrate $\left(\mathrm{AgNO}_{3}\right)$ solution and incubated in a rotary shaker for $2 \mathrm{~h}$, then at room temperature for $24 \mathrm{~h}$ in the dark until the brownish color was developed which indicated the formation of AgNPs (Parashar et al., 2009).

Characterization of AgNPs

Visual observation: The reduction of metal ions was roughly monitored by visual inspection of the solution by the conversion of the pale yellow reaction mixture to a colored solution (Fang et al., 2005).

UV-vis absorbance spectroscopy analysis: The reduction of pure $\mathrm{Ag}^{+}$ions in $\mathrm{AgNO}_{3}$ into AgNPs was monitored periodically by UV-vis spectroscopy (T80 UV-vis spectrophotometerdouble beam) after the dilution of the samples with deionized water (Raut et al., 2009). A UVvis spectrograph of the AgNPs was recorded by using a quartz cuvette with water as reference. The UV-vis spectrometric readings were recorded at 200-800 nm (Leela \& Vivekanandan, 2008).

Transmission electron microscope (TEM) analysis of AgNPs: The suspension containing AgNPs was sampled by TEM analysis using (JEOL-TEM $100 \mathrm{CX}$ ) at the Electron Microscopic Unit, Faculty of Science, Alexandria University. TEM samples were prepared by placing a drop of the suspension of AgNPs solutions on carbon-coated copper grids and allowing water to evaporate. The samples on the grids were allowed to dry for $4 \mathrm{~min}$. The shape and size of AgNPs were determined from TEM micrographs (Elavazhagan \& Arunachalam, 2011). 
Energy dispersive spectroscopy (EDS): Elemental analysis was carried using an Energy Dispersive X-ray (EDS) spectrometer at the special unit of Electron Microscope, Faculty of Science, Alexandria University. Link ISIS analyzer programmed attached with Scanning Electron Microscope (SEM) was employed for the data collection.

Plant material, growth conditions, and treatments

Wheat grains (Triticum aestivum L., cv. Sakha 61) were purchased from Agricultural Research Center, Giza, Egypt. Prior to germination, the grains were soaked in $0.1 \%$ sodium hypochlorite solution for $3 \mathrm{~min}$ then washed thoroughly several times with distilled water. To determine the effect of seed priming with AgNPs on germination of wheat under salinity stress, a factorial laboratory experiment of completely randomized design with 4 replicates was carried out. The sterilized grains were soaked either in AgNPs solution (1 $\mathrm{mg} \mathrm{L}^{-1}$ ) or distilled water (as control) for $4 \mathrm{~h}$ at room temperature. Twenty grains were allocated at random in Petri dishes ( $15 \mathrm{~cm}$ diameter) containing filter paper moistened with $20 \mathrm{ml}$ of either distilled water or salt concentration $(25 \mathrm{mM}$ and $100 \mathrm{mM}$ $\mathrm{NaCl}$ ) covered with lid, and incubated at natural environmental conditions (photoperiod of $16 \mathrm{~h} / 8 \mathrm{~h}$ light/dark, $28 / 23 \pm 2^{\circ} \mathrm{C}$ light/dark temperature; light intensity PPFD, $23 \mu \mathrm{mol} \mathrm{m} \mathrm{m}^{-2} \mathrm{~s}^{-1}$.

\section{Germination and growth parameters}

Germinating grains were counted based on 2 $\mathrm{mm}$ radicle emergence on the $2^{\text {nd }}$ day subsequently complete seed germination was established on $5^{\text {th }}$ $10^{\text {th }}$ day (with plumule and radicle). Germination percentages were calculated according to Ruan et al. (2002) using the following equations:

Germination percentage $(\mathrm{GP} \%)=(\mathrm{Gf} / \mathrm{n}) \times 100$

where $\mathrm{Gf}$ is the total number of germinated seeds and $\mathrm{n}$ is the total number of seeds used in the test.

Radicle and plumule lengths were measured at 3 and 5-days of the experiment. After 10 days, 3 seedlings were randomly selected in each plate to measure both shoot and root fresh and dry biomasses, photosynthetic pigments, chlorophyll fluorescence and plant phytohormones.

\section{Estimation of photosynthetic pigments}

The photosynthetic pigments were determined according to methods described by Moran \& Porath (1980) using N,N-dimethyl formamide (DMF), total carotenoid content was calculated according to Wellburn (1994) and related to leaf weight. The chlorophyll stability index (CSI) was measured as noted by Sivasubramaniawn (1992) using the formula:

$\mathrm{CSI}=($ total $\mathrm{Chl}$ content in stressed leaves/total $\mathrm{Chl}$ content in control leaves) $\times 100$

Measurement of chlorophyll fluorescence

Measurements of Chl fluorescence was performed with OS-30P pulse modulated chlorophyll fluorimeter (Opti-sciences, Hudson, and USA) following the procedure described by van Kooten \& Snel (1990).

\section{Determination of plant phtyohormones}

Endogenous hormones, namely auxins (as 1-Naphthalene acetic acid, NAA and Indole3-butyric acid, IBA), abscisic acid (ABA) and cytokinins (as benzylamino purine, BAP) were extracted and purified as described by Kettner \& Doerffling (1995). The plant leaves (1 g) were ground in $80 \%$ methanol at $4{ }^{\circ} \mathrm{C}$ for $72 \mathrm{~h}$ with an antioxidant butylated hydroxyl toluene. The extract was centrifuged and the supernatant was reduced to aqueous phase using rotary evaporator. The $\mathrm{pH}$ of aqueous phase was adjusted to 2.5-3.0 and extracted four times with half volume of ethyl acetate. The ethyl acetate was dried completely using rotary evaporator and the dried sample was re-dissolved in $1 \mathrm{~mL}$ of methanol $(100 \%) .50 \mu \mathrm{L}$ of methanol extract was analyzed using HPLC system (Agilent technologies 1200 series and UV/VIS detector 200 LC, USA) equipped with a $5-\mu \mathrm{m}$ column (Exclipse XDB -18; 4.6 X $150 \mathrm{~mm}$; Brownlee). The solvent used was methanol- $2 \%$ acetic acid and $\mathrm{H}_{2} \mathrm{O}$ $(40: 20: 20)$ as the mobile phase, run isocratically at flow rate of $1 \mathrm{~mL} / \mathrm{min}$. The detector was set at $254 \mathrm{~nm}$ for the integration of peak areas after calibration with the external standard.

\section{Statistical analysis}

Statistical analysis of the results was carried out according to Duncan's multiple range tests using SPSS-20. Data were subjected to one-way ANOVA following the method of Sokal \& Rohlf (1995). Differences between treatment-means were considered statistically significant at $p \leq 0.05$.

\section{Results}

\section{Characterization of AgNPs}

Visual observation

The color of the extract changes from pale yellow to brown color after addition of $3 \mathrm{mM}$ $\mathrm{AgNO}_{3}$ which indicates the reduction of silver ions (Fig. 1A). 

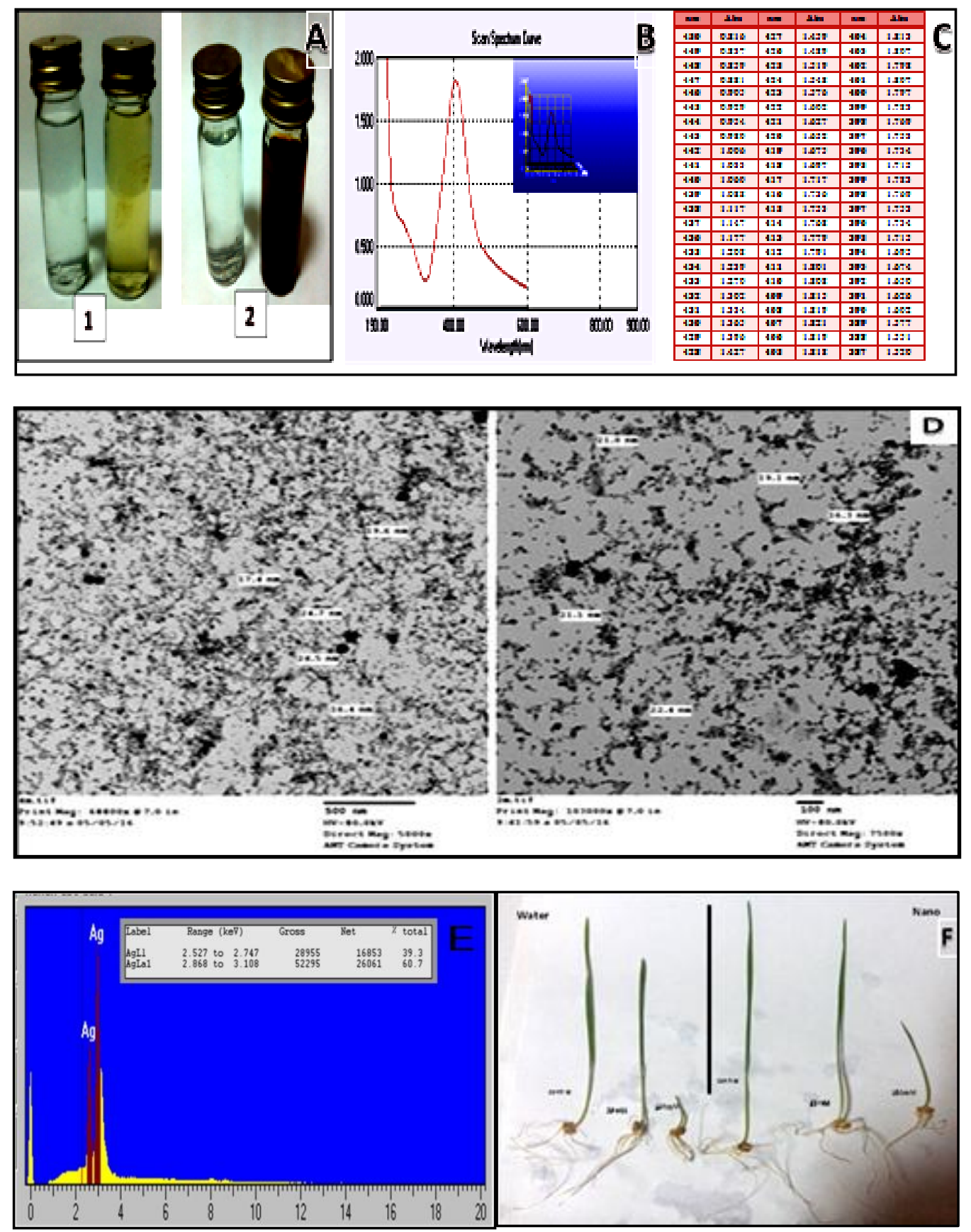

Fig. 1. Biosynthesis and confirmation of Ag-NPs. (A), visual observation; (B, C), UV-Vis absorption spectrum; (D), transmission electron microscopy (TEM) micrograph; (E), EDS spectra of biosynthesized AgNPs; and (F), the effect of AgNPs-priming on the germination and growth of 10-day old wheat seedling grown at 25 and $100 \mathrm{mM}$ NaCl.

UV-vis absorbance spectroscopy analysis

The presence of nanoparticles was confirmed by obtaining a spectrum in the visible range of 400-430 nm using UV-visible spectrophotometer (Fig. 1B and C).

Transmission electron microscope analysis of AgNPs

The TEM image has been employed to characterize the size, shape and morphology of biosynthesized AgNPs. The biosynthesized AgNPs are spherical and semispherical in shape with a smooth surface morphology and a diameter ranging from 15 to $30 \mathrm{~nm}$ (Fig. 1D).

Energy dispersive spectroscopy (EDS)

The presence of elemental silver signal was confirmed by EDS as shown in Fig. 1E. The presence 
of an optical absorption band at 2.527 to 2.747 Kev and 2.868 to 3.108 reveals the presence of pure metallic AgNPs. The spectrum shows mainly $\operatorname{Ag}(39.3 \%)$ and (60.7\%), respectively.

\section{Salinity and wheat growth attributes}

From Fig. 1F and Fig. 2 it is shown that salt stress resulted in an adverse effect on wheat growth as reflected by a significant decrease in the GP, radicle and plumule lengths as well as fresh and dry biomasses of 10-days old wheat seedling. However, AgNPs priming has greatly shifted off the inhibitory effect of the salt stress on the growth of wheat plants. The highest reduction of GP was recorded at $100 \mathrm{mM} \mathrm{NaCl}$ and amounted 55\%. On the contrary, GP increased conspicuously in response to AgNPs priming reaching 90\% at $100 \mathrm{mM} \mathrm{NaCl}$. The application of the regression analysis resulting in a value of coefficient $\left(\mathrm{R}^{2}\right)$ of determination of about 0.942 and 0.999 for waterand AgNPs- primed, respectively in presence of $\mathrm{NaCl}$ (Fig. 2A and B).

In the water-primed seedling grown at $100 \mathrm{mM}$ $\mathrm{NaCl}$, the inhibition percentages of shoots and roots lengths were 74 and $81 \%$, respectively, compared with control. The corresponding values in AgNPsprimed plants were $22 \%$ and $58 \%$, respectively (Fig. 2C and D). In addition, the fresh and dry biomasses of roots of AgNPs-primed-100 mM $\mathrm{NaCl}$ treated seedlings were 1.4 and 1.4-fold that of $100 \mathrm{mM} \mathrm{NaCl}$-treated seedlings, respectively. The corresponding values for shoots were 1.6 and 1.7- fold, respectively (Fig. 2E and F).

As shown in Fig. 3, salt treatment resulted in a significant reduction in the total photosynthetic pigment contents, particularly at $100 \mathrm{mM} \mathrm{NaCl}$ and this reduction was mainly attributed to the reduction in chlorophyll a (Chl a). Nonetheless, AgNPs priming could improve the chlorophyll concentration in the seedlings exposed to saltstress. Additionally, $100 \mathrm{mM} \mathrm{NaCl}$ treatment showed significant reduction in the percentages of CSI reaching $69 \%$, the corresponding value of AgNPs-primed plants was $42 \%$.

The ratio $\mathrm{F}_{\mathrm{v}} / \mathrm{F}_{\mathrm{m}}$ which reflects the quantum efficiency for photochemistry of PSII decreased with increasing salt concentrations being not detected at high salt concentration (100 mM). Whereas, the decrease in the photosynthetic quantum efficiency reached only $13 \%$ in AgNPsprimed-100 $\mathrm{mM}$ treated plants with respect to the control (Table 1).

The HPLC analysis of endogenous phtyohormones of wheat plants exposed to 100 $\mathrm{mM} \mathrm{NaCl}$ and/or nano-priming revealed that salinity decreased shoot auxins namely NAA and IBA concentration by $27 \%$ and $47 \%$, respectively compared to controls, while the corresponding values for root were only $15 \%$ and $8 \%$ (Table 2, Fig. 4). Endogenous cytokinin represented by BAP was also reduced under salt stress and the reduction value ranged from $13-14 \%$ in both shoots and roots. On the other hand, the ABA contents of both shoots and roots increased with the exposure of wheat plants to elevated $\mathrm{NaCl}$ stress reaching 1.9-and 3.9-fold, respectively compared with the control ones. AgNPs-priming alone or in combination with salt stress had an inductive effect on the endogenous auxin and cytokinins while it decreased the ABA content, compared with their respective controls.

\section{Discussion}

Most of the plants contain an ample of free radical scavenging molecules such as phenolic and nitrogen compounds, vitamins, reducing sugar, terpenoids and some other metabolites that are rich in antioxidant activity (Salam et al., 2012). Recently, Abou-Zeid et al. (2014) reported that Capparis spinosa contains many phenolics (24.12 $\mathrm{mg} / \mathrm{g} \mathrm{DM})$ and flavonoids (16.47 mg/g DM); they detected chlorogenic, caffeic, gallic, 2,5-dihydroxy benzoic and 3,5- dicaffeoyl quinic acid as well as phloridzin and catechin. Nowadays, AgNPs are a very important part of nanotechnology mainly because they do not induce modification on living cells. In the present investigation, an attempt was made to use green biochemistry for obtaining AgNPs by using aqueous plant extract of Capparis spinosa L. as a simple, non-toxic and ecofriendly green material and also exploring the possibility of using nanopriming with biogenic nanoparticles in counteract the inhibitory effect of salinity on the germination and growth of wheat grains.

The nanoparticles formed exhibit brownish color in aqueous solution which indicated the reduction of silver ions and formation of AgNPs. The brown color of AgNPs became visible due to excitation in surface plasmon vibrations (absorbance 400-430 nm) which is due to the electron oscillations that collectively gather around the surface of metal particles. The results obtained for characterization of AgNPs were in accordance with those obtained by Pandit (2015) and Benakashani et al. (2016) who reported the synthesis of AgNPs from Brassica nigra and Capparis spinosa. 

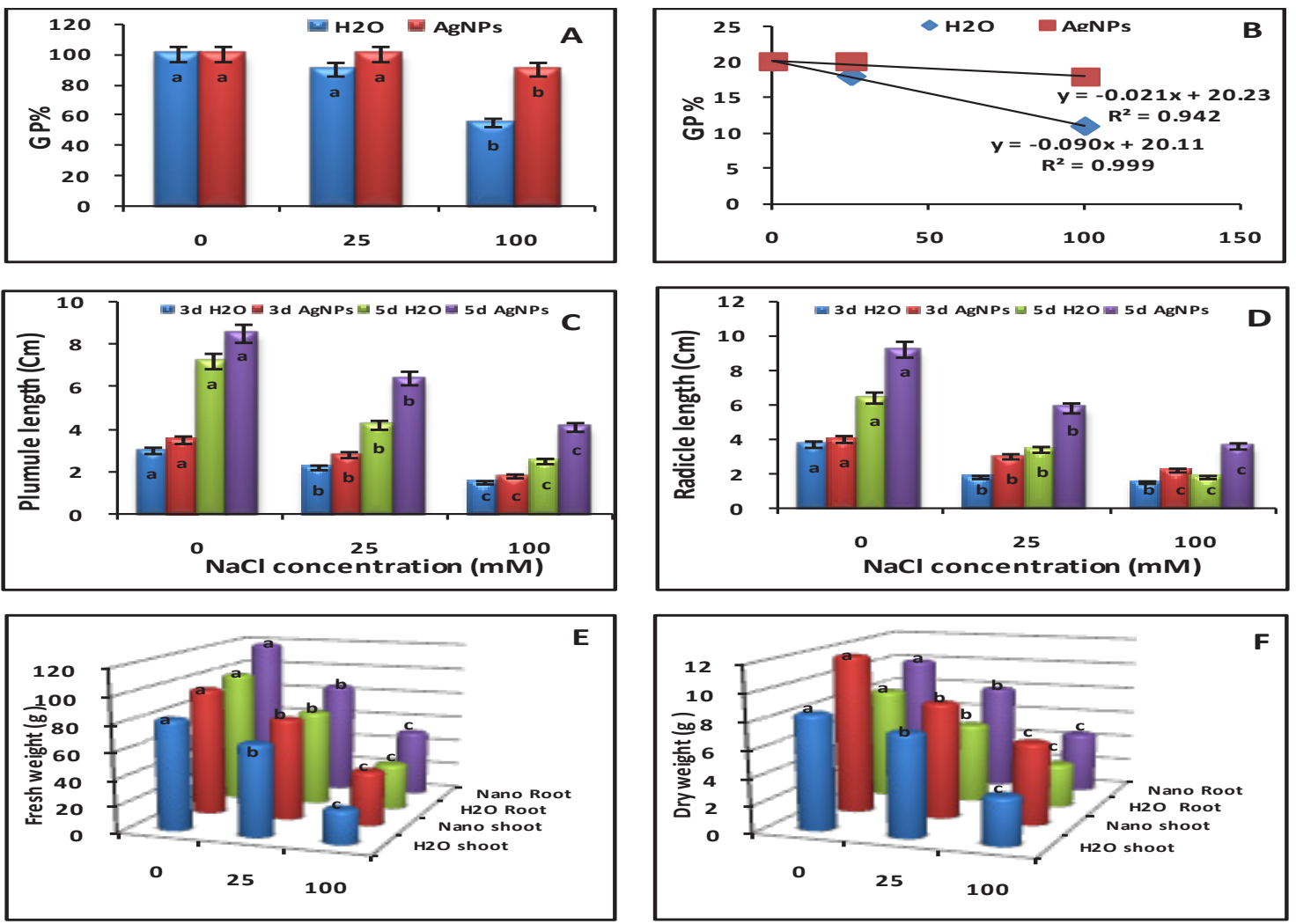

Fig. 2. The effect of AgNPs-priming on: (A) Germination percentages GP\%; (B) Regression analysis; (C) Plumule length; (D) Radicle length; (E) Root and shoot fresh biomass; and (F) Root and shoot dry biomass of 10day old wheat seedling grown at 25 and $100 \mathrm{mM} \mathrm{NaCl}$. Values are the means of 3 independent replicates $\pm \mathrm{SE}$; means followed by different letters are significantly different at $\mathbf{P} \leq 0.05$ to Duncan's multiple comparison test..
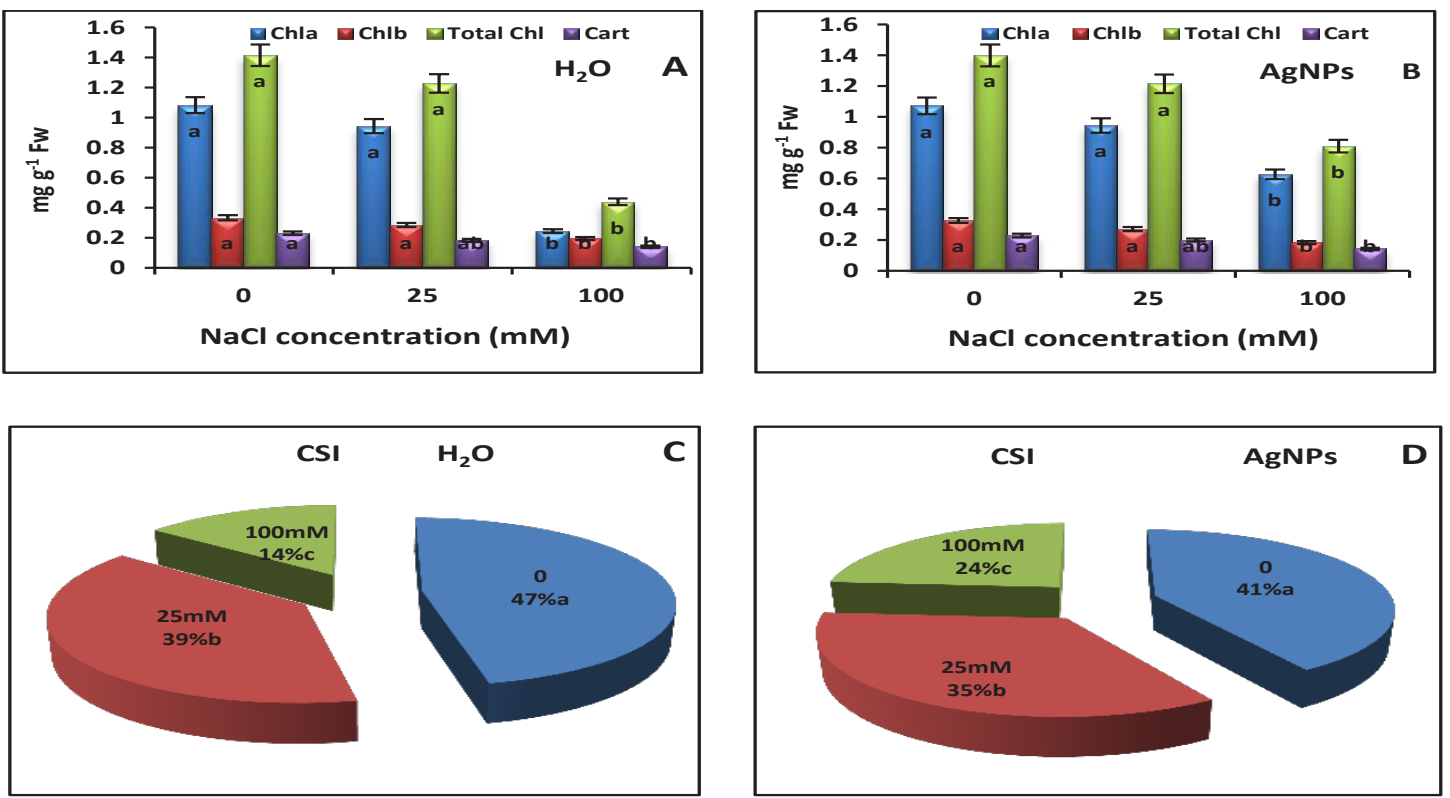

Fig. 3. The effect of AgNPs-priming on: (A, B) Photosynthetic pigments; (C, D) Chlorophyll stability index (CSI) of 10-day old wheat seedling grown at 25 and $100 \mathrm{mM} \mathrm{NaCl}$. Values are the means of 3 independent replicates $\pm \mathrm{SE}$; means followed by different letters are significantly different at $\mathrm{P} \leq 0.05$ according to Duncan's multiple comparison test. 

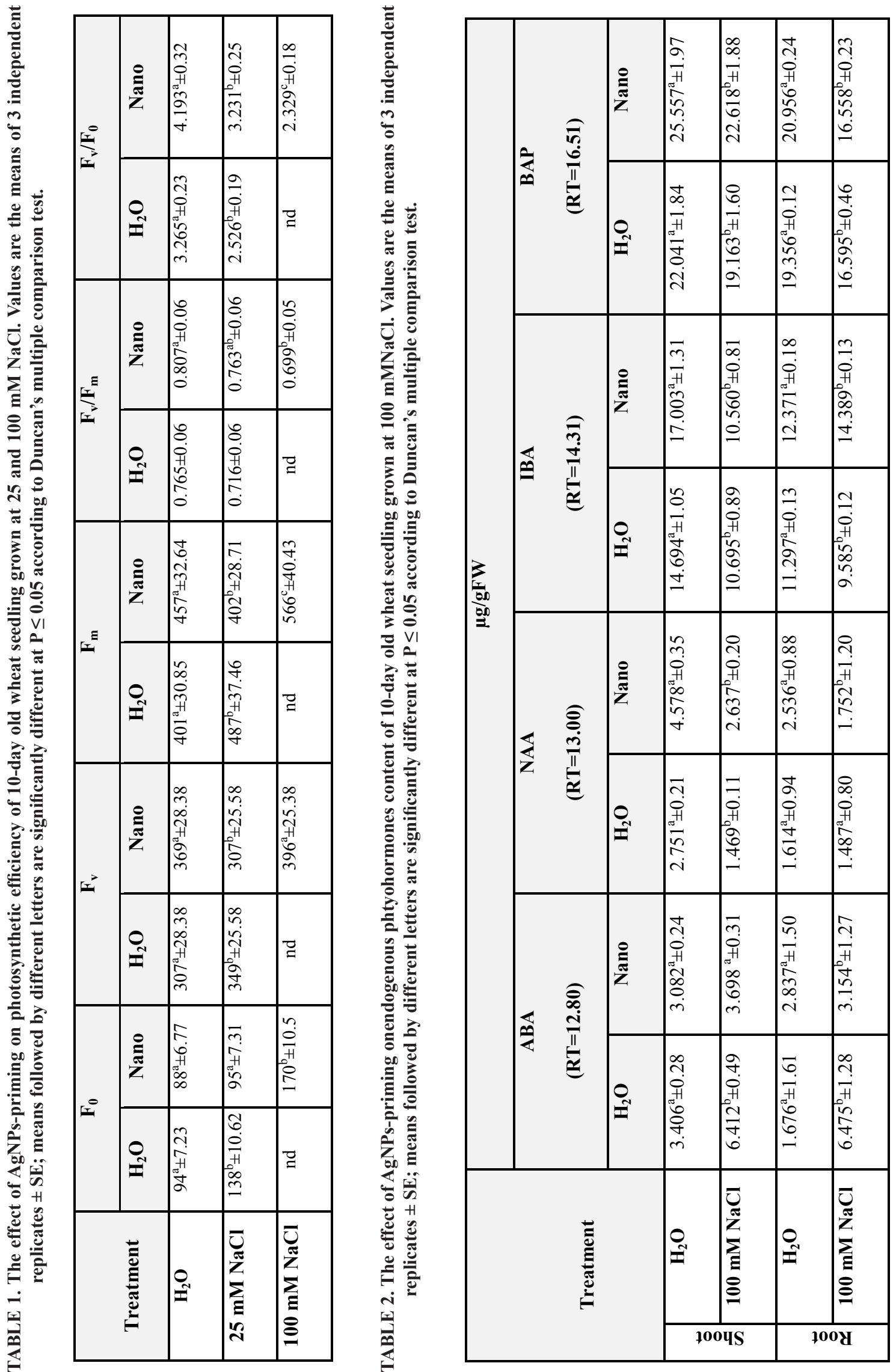

Egypt. J. Bot. 58, No.1 (2018) 


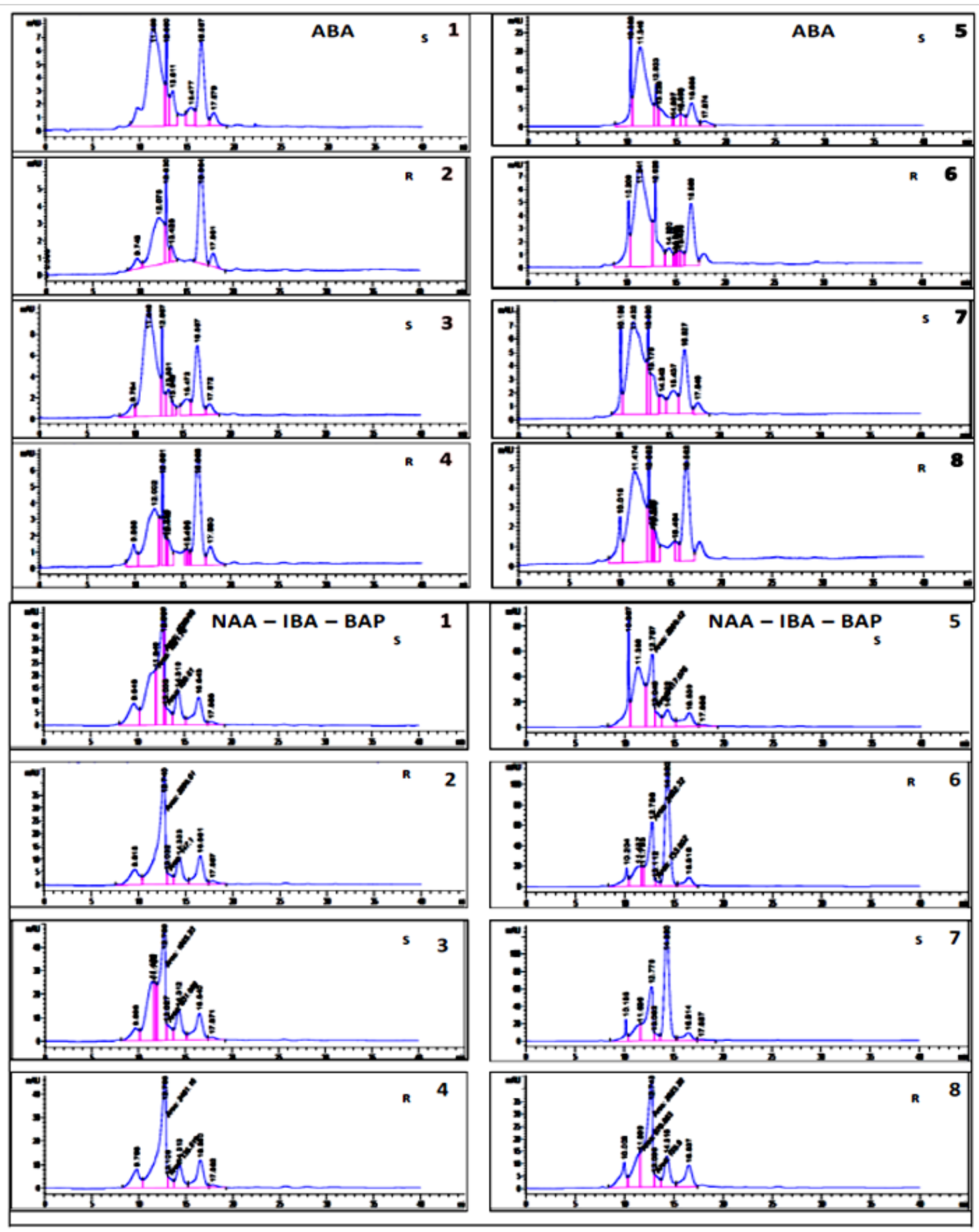

Fig. 4. HPLC chromatogram showing the effect of AgNPs-priming on endogenous phytohormone content of 10day old wheat seedling grown at 25 and $100 \mathrm{mMNaCl}$.

$\mathrm{S}=$ Shoot, $\mathrm{R}=$ Root; $(1,2) \mathrm{H}_{2} \mathrm{O}$ priming, $(3,4) \mathrm{H}_{2} \mathrm{O}$ priming $+100 \mathrm{mMNaCl},(5,6)$ AgNPs priming; $(7,8)$ AgNPs priming + $100 \mathrm{mMNaCl}$. 
The inhibitory effect of salt stress on wheat growth is consistent with several reports in other plant species (Jafar et al., 2012; Srivastava et al.,2015 and Ismail et al., 2017). Debez et al. (2004) reported that salinity has inhibitory effects on water uptake, germination of seeds and seedling root elongation. Furthermore, Farooq et al (2015) postulated that salt stress influences seed germination primarily due to hyper-osmotic stress resulting from toxic effects of sodium and chloride ions on germinating seeds or by altering protein synthesis. Thus, the impaired growth of wheat seedlings could be due to the disturbance of plasma membrane integrity, the poor root growth as well as to the inhibition of cell division and/ or restriction of cell elongation. Moreover, the reduction in plumule and root lengths and hence the growth, might be attributed to the disturbance of biosynthesis and allocation of hormonal signals in the roots (Ali \& Abbas, 2003).

The imposition of salt stress caused a significant reduction in the content of all photosynthetic pigments including carotenoids. It is noteworthy also in this study that these observations were coincided with a decrease in $\mathrm{F}_{\mathrm{v}} / \mathrm{F}_{\mathrm{m}}$ ratios. The reduction of $\mathrm{F}_{\mathrm{v}} / \mathrm{F}_{\mathrm{m}}$ ratio in $\mathrm{NaCl}$ stressed wheat plants may be due to reduction in the $\mathrm{F}_{\mathrm{m}}$ value, which indicates increased energy dissipation, dissociation of the light harvesting antennae from the PSII core and denaturation of the PSII reaction centre (Santos et al., 2001). Similar observations were recorded in maize (Qu et al. 2012) and rice (Senguttuvel et al., 2014) grown under salt stress. The suppression in photosynthetic pigments content has been reported to be related to the inhibition of specific enzymes responsible for their synthesis and induction of some degradative enzymes such as chlorophyllase as well as destruction of the photosynthetic machinery (Yamane et al., 2008).

In recent years, accumulating evidences show that metal nanoparticles are considered to modify physiological and biochemical processes in plants thereby affecting their germination percentages and growth favorably or otherwise (Hossain et al., 2015). Under the prevailing experimental conditions, AgNPs -priming could counteract the inhibitory effect of salinity on the germination and growth of wheat grains. This may be explained by the enhancement of the different biochemical reactions and water absorption as indicated by a marked increase in GP, shoot length and other growth characteristics as well as photosynthetic pigments, CSI and photosynthetic efficiency. These results were in agreement with those of Siddiqui et al. (2015). Earlier, Sharma et al. (2012) showed enhanced fresh weight, root and shoot lengths, vigor index and antioxidant status of Brassica juncea seedlings in response to AgNPs-priming. Abou-Zeid \& Mostafa (2014) reported that root tips of wheat and barley germinated seeds treated with AgNPs showed cytological changes and significant increase in mitotic index as well as photosynthetic pigments and chlorophyll fluorescence.

Additionally, under the prevailing experimental conditions, AgNPs -priming could ameliorate the inhibitory effect of salinity on the germination and growth of wheat grains. This may be explained by the enhancement of the different biochemical reactions and water absorption as indicated by a marked increase in GP, shoot length and other growth characteristics. Similarly, BhatiKushwaha et al. (2013) and Almutairi (2015) reported that the AgNPs appeared to mitigate the deleterious effect of chilling and salinity in wheat and Solanum lycopersicum L., respectively. Likewise, nano-silicon as well as nano zinc oxide were capable of improving salt resistance in some plants (Sedghi et al., 2013 and Kalteh et al., 2014). Taran et al. (2017) recorded an increase of carotenoid content in the leaves of winter wheat seedlings grown from seeds treated with zinc and copper nanoparticles after drought action which demonstrates the well-known adaptation mechanism. In contrast to this view, there was no significant change in carotenoid contents of wheat leaves in response to either salt stress or AgNPspriming. However, AgNPs-priming particularly at $100 \mathrm{mM} \mathrm{NaCl}$ could stimulate the growth of wheat seedling as evident by the significant increase in FW, DW, photosynthetic pigment content and $\mathrm{F}_{\mathrm{v}} / \mathrm{F}_{\mathrm{m}}$ ratios; where the chlorophyll fluorescence parameters were not detectable in water-primed seedling grown at $100 \mathrm{mM} \mathrm{NaCl}$. These results may indicate the development of other adaptive mechanisms to salt stress.

One of the most important plant mechanisms to overcome drought and salt-induced damages is the alteration in endogenous phytohormone levels which modulate several responses during the whole plant life cycle both under stress and non-stress conditions (Ahmadi et al., 2010). Data of this study revealed that increasing salinity level leads to a sharp change in the balance of endogenous phytohormones; accumulation of 
ABA was associated with decreased levels of growth stimulator (auxins and cytokinins) in wheat shoots and roots. Changes in hormone levels in wheat plant might be an initial process controlling growth reduction due to salinity. For instance, Younis et al. (2003) observed increased ABA levels at the expense of IAA in maize under salinity stress; this modification may lead to stomatal closure to minimize water loss as a consequence of salinity-induced osmotic stress. Higher ABA levels in salt-stressed wheat may help to minimize water loss and may even regulate growth promotion. Sadak et al. (2013) suggested that the decrement in the concentration of auxins and cytokinins in salt-stressed plants could be referred to reduction of their biosynthesis resulting from osmotic stress disturbance and/or their destruction and transformation to inactive bound forms. On the other hand, salt-stressed wheat plants primed with AgNPs showed enhanced auxins and cytokinin concentrations and reduction in ABA. There is also report on cells treated with AgNPs to have upregulation in the expression of genes involved in ABA signaling pathway, IAA biosynthesis,... etc. (Arase et al., 2012). Recently, El-Batal et al. (2016) reported that foliar application of AgNPs had a stimulatory effect on the IAA, $\mathrm{GA}_{3}$, total cytokinins, and an inhibitory effect on ABA contents as compared with untreated common bean plants. The authors suggested that changes in phytohormones may be involved in gene expression regulating the signalling activities or levels of growth regulating substances through having a direct impact on the activities of oxidoreductive enzymes related to hormonal metabolism. In turn, such changes may lead to an increase of the metabolic compounds, which can also explain the increased growth parameters in AgNP-primed salt stressed wheat plants, as compared with control ones (El-Batal et al., 2016). In addition, AgNPs acted as inhibitors of ethylene perception and could interfere with ethylene biosynthesis (Syu et al., 2014). However, Information on the uptake of nanoparticles by plants, as well as on the potential mechanisms of senescence inhibition, remains largely unknown and must be addressed in future research.

\section{Conclusion}

The present work demonstrated a rapid green synthesis of AgNPs from Capparis spinosa L. The findings emphasis that seed priming with AgNPs is a useful way to increase seedling tolerance under salinity conditions. Increasing seed germination, seedling growth, chlorophyll content and photosynthetic efficiency along with changing endogenous phytohomones balance were a manifestation of plant adaptation to salinity at the influence of the AgNPs. Nevertheless, further physiological and molecular studies are required to determine the exact cascade of changes and the particular genes that are induced to bring such an effect.

Acknowledgments: The authors are grateful to Prof. Dr. Laila Mostafa Bidak, Botany and Microbiology Department, Faculty of Science, Alexandria University for providing Capparis spinosa plant.

\section{References}

Abou-Zeid, H.M., Bidak, L.M. and Gohar, Y.M. (2014) Phytochemical screening and antimicrobial activities of some wild medicinal plants of the western mediterranean coastal region, Egypt. Int. J. Pharm. Sci. Res. 5, 3072-3080.

Abou-Zeid, H.M. and Moustafa, Y. (2014) Physiological and cytogenetic response of wheat and barley to silver nanopriming treatment. Int. J. Appl. Biol. Pharm. Technol. 5, 265-278.

Ahmadi, S.H., Andersen, M.N., Plauborg, F., Poulsen, R.T., Jensen, C.R., Sepaskhah, A.R. and Hansen, S. (2010) Effects of irrigation strategies and soils on field grown potatoes: Yield and water productivity. Agric. Water Management, 97, 1923-1930

Ali, R.M. and Abbas, H.M. (2003) Response of salt stressed barley seedlings to phenylurea. Plant Soil Environ. 49, 158-162.

Almutairi, Z.M. (2015) Influence of silver nanoparticles on the salt resistance of tomato (Solanum lycopersicum L.) during germination. Int. J. Agric. Biol.18(2), 449-457.

Al-Snafi, A.E. (2015) The chemical constituents and pharmacological effects of Capparis spinosa - An overview. Ind. J. Pharmac. Sci. Res. 5(2), 93-100.

Arase, F., Nishitani, H., Egusa, M., Nishimoto, N., Sakurai, S., Sakamoto, N. and Kaminaka, H. (2012) IAA8 involved in lateral root formation interacts with the TIR1 auxin receptor and ARF transcription factors in Arabidopsis. PLoS ONE, 7, e43414.

Bansal, M., Bansal, A., Sharma, M. and Kanwar, P. (2015) green synthesis of gold and silver nanoparticles. RJPBCS, 6(3), 1710-1716.

Benakashani, F., Allafchian, A.R. and Jalali, S.A.H. 
(2016) Biosynthesis of silver nanoparticles using Capparis spinosa L. leaf extract and their antibacterial activity. Karbala Int. J. Modern Sci. 2, 251-258.

Bhati-Kushwaha, H., Kaur, A. and Malik, C.P. (2013) The synthesis and role of biogenic nanoparticles in overcoming chilling stresses. Ind. J. Plant Sci. 2, 54-62.

Chunthaburee, S., Sanitchon, J., Pattanagul, W. and Theerakulpisut, P. (2014) Alleviation of salt stress in seedlings of black glutinous rice by seed priming with spermidine and gibberellic acid. Not. Bot. Horti. Agrobo. 42(2), 405-413.

Debez, A., Ben-Hamed, K., Grignon, C. and Abdelly, C. (2004) Salinity effects on germination, growth, and seed production of the halophyte Cakile maritime. Plant and Soil, 262, 179-189.

Dwivedi, A.D. and Gopal, K. (2010) Biosynthesis of silver and gold nanoparticles using Chenopodium album leaf extract. Colloids Surfaces $A$ : Physicochem. Eng. Aspec. 369, 27-33.

Ekhtiyari, R. and Moraghebi, F. (2011) The study of the effects of nano silver technology on salinity tolerance of cumin seed (Cuminum cyminum L.). Plant Ecosyst. 7, 99-107.

Ekhtiyari, R., Mohebbi, H. and Mansouri, M. (2011) The study of the effects of nano silver technology on salinity tolerance of Foeniculum vulgare mill. Plant Ecosyst. 7, 55-62.

El-Batal, A.I., Gharib, F.A., Ghazi, S.M., Hegazi, A.Z. and Abd El Hafz, A.G.M. (2016) Physiological responses of two varieties of common bean (Phaseolus vulgaris L.) to foliar application of silver nanoparticles. Nanomat. Nanotechnol. 6, 1-16.

Elavazhagan, T. and Arunachalam, K.D. (2011) Memecylon edule leaf extract mediated green synthesis of silver and gold nanoparticles. Int. J. Nanomed. 6, 1265-1278.

Fang, J., Zhang, C. and Mu, R. (2005) The study of deposited silver particulate films by simple method for efficient SERS. Chem Phy. Lett. 401, 271-275.

Farooq, M., Hussain, M., Abdul Wakeel and Siddique, K.H.M. (2015) Salt stress in maize: Effects, resistance mechanisms, and management. Agron. Sustain. Dev. 35, 461-481.

Ghobadi, M., Shafiei-Abnavi, M., Jalali-Honarmand, S., Ghobadi, M.E. and Mohammadi, G.R. (2012) Does $\mathrm{KNO}_{3}$ and hydropriming improve wheat
(Triticum aestivum L.) seeds germination and seedlings growth? Annals of Biol. Res. 3, 31563160 .

Hossain, Z., Mustafa, G. and Komatsu, S. (2015) Plant responses to nanoparticle stress. Int. J. Mol. Sci. 16, 26644-26653.

Hussain, M.I., Lyra, DA., Farooq, M., Nikoloudakis, N. and Khalid, N. (2016) Salt and drought stresses in safflower: A review. Agron. Sustain. Dev. 36(1), 4-13.

Ismail, G.S.M., Ali, A.S., Eldebawy, E.M.S. and Saber, N.E. (2017) Role of cellular NADP+/NADPH ratio in the acclimative mechanism of two common bean cultivars toward salt stress. J. Appl. Bot. Food Qual. 90, 43-51.

Jafar, M.Z., Farooq, M., Cheema, M.A., Afzal, I., Basra, S.M.A., Wahid, M.A., Aziz, T. and Shahid, M. (2012) Improving the performance of wheat by seed priming under saline conditions. J. Agron. Crop Sci. 198, 38-45.

Kalteh, M., Alipour, Z.T., Ashraf, S., Aliabadi, M.M. and Nosratabadi, A.F. (2014) Effect of silica nanoparticles on basil (Ocimum basilicum) under salinity stress. J. Chem. Health Risks, 4, 49-55.

Kettner, J. and Doerffling, K. (1995) Biosynthesis and metabolism of abscisic acid in tomato leaves infected with Botrytis cincerea. Plant, 196, 627634.

Kumar, G., Purty, R.S., Sharma, M.P., Singla-Pareek, S.L. and Pareek, A. (2009) Physiological responses among Brassica species under salinity stress show strong correlation with transcript abundance for SOS pathway related genes. J. Plant Physiol. 166, 507-520.

Leela, A. and Vivekanandan, M. (2008) Tapping the unexploited plant resources for the synthesis of silver nanoparticles. Afr. J. Biotech. 7, 3162- 3165.

Moran, R. and Porath, D. (1980) Chlorophyll determination in intact tissues using N,N- 352 dimethylformamide. Plant Physiol. 65, 478-479.

Morari, F., Meggio, F., Lunardon, A., Scudiero, E., Forestan, C., Farinati, S. and Varotto, S. (2015) Time course of biochemical, physiological, and molecular responses to field-mimicked conditions of drought, salinity, and recovery in two maize lines. Front Plant Sci. 6, 1-15.

Musante, C. and White, J.C. (2012) Toxicity of silver and copper to Cucurbita pepo: differential effects 
of nano and bulk-size particles. Environ. Toxicol. 27, 510-517.

Pandit, R. (2015) Green synthesis of silver nanoparticles from seed extract of Brassica nigra and its antibacterial activity. Nusant Ara Biosc. E. 7(1), 15-19.

Parashar, V., Parashar, R., Sharma, B. and Pandey, A. (2009) Parthenium leaf extract mediated synthesis of silver nanoparticles: A novel approach toward weed utilisation. Dig. J. Nanomater. Biostruct. 4, 45-50.

Qu, C., Liu, C., Gong, X., Li, C., Hong, M., Wang, L. and Hong, F. (2012) Impairment of maize seedling photosynthesis caused by a combination of potassium deficiency and salt stress. Environ. Exp. Bot. 75, 134-141.

Raut, R., Jaya, S.L., Niranjan, D.K., Vijay, B.M. and Kashid, S. (2009) Photosynthesis of silver nanoparticle using Gliricidia sepium (Jacq.). Curr Nanosci. 5(1), 117-122.

Ruan, S., Xue, Q., Tylkowska, K. (2002) The influence of priming on germination of rice (Oryza sativa L.) seeds and seedling emergence and performance in flooded soils. Seed Sci. Technol. 30, 61-67.

Sadak, M.S., Abd Elhamid, E.M. and Mostafa, H.M. (2013) Alleviation of adverse effects of salt stress in wheat cultivars by foliar treatment with antioxidants I. Changes in growth, some biochemical aspects and yield quantity and quality. American-Eurasian J. Agric. Environ. Sci. 13, 1476-1487.

Salam, H.A., Rajiv, P., Kamaraj, M., Jagadeeswaran, P., Gunalan, S. and Sivaraj, R. (2012) Plants: Green route for nanoparticle synthesis. Int. Res. J. Biol. Sci. 1, 85-90.

Santos, V., Campos, A., Azevedo, H. and Caldeira, G. (2001) In situ and in vitro senescence induced by $\mathrm{KCl}$ stress: Nutritional imbalance, lipid peroxidation and antioxidant metabolism. J. Exp. Bot. 52, 351360 .

Senguttuvel, P., Vijayalakshmi, C., Thiyagarajan, K., Kannanbapu, J.R., Kota, S., Padmavathi, G., Geetha, S., Sritharan, N. and Viraktamath, B.C. (2014) Changes in photosynthesis, chlorophyll fluorescence, exchange parameters and osmotic potential to salt stress during early seedling stage in rice (Oryza sativa L.). SABRAO J. Breed. Genet. 46(1), 120-135.

Sedghi, M., Hadi, M. and Toluie, S.G. (2013) Effect of nano zinc oxide on the germination parameters of soybean seeds under drought stress. Ann. W.U.T.Ser. Biol. XVI, 73-78.

Sharma, P., Bhatt, D., Zaidi, M.G., Saradhi, P.P., Khanna, P.K. and Arora, S. (2012) Silver nanoparticle-mediated enhancement in growth and antioxidant status of Brassica juncea, Appl. Biochem. Biotechnol. 167(8), 2225-2233.

Shelar, B.G. and Chavan, M.A. (2015) Myco-synthesis of silver nanoparticles from Trichoderma harzianum and its impact on germination status of oil seed. Biolife, 3, 109-113.

Siddiqui, M.H., Al-Whaibi, M.H., Firoz, M. and AlKhaishany, M.Y. (2015) Role of Nanoparticles in Plants. In: "Nanotechnology and Plant Sciences: Nanoparticles and their Impact on Plants", Siddiqui, M.H., Al-Whaibi, M.H., Firoz, M. (Ed.), pp. 19-35. Springer International Publishing, Switzerland, ISBN: 9783319145020.

Sivasubramaniawn, K. (1992) Chlorophyll stability index: Methods for determining drought hardness of Acacia species. Nitrogen Fixing Tree Res. Reports, 10, 111-112.

Sokal, R.R. and Rohlf, F.J. (1995) "Biometry: The Principles and Practice of Statistics in Biological Research". Freeman, W.H., Company, New York, USA, 271-356.

Sorescu, A., Nută, A., Ion, R. and Ioana-Raluca, S. (2016) Green synthesis of silver nanoparticles using plant extracts. The $4^{\text {th }}$ International Virtual Conference on Advanced Scientific Results. Chem. Sci. pp.188-193.

Srivastava, A.K., Srivastava, S., Lokhande, V.H., Souza, F.D. and Suprasanna, P. (2015) Salt stress reveals differential antioxidant and energetic responses in glycophte (Brassica juncea L.) and halophyte (Sesuvium portulacastrum L.). Fron. Environ. Sci. 3, 1-9.

Syu, Y.Y., Hung, J.H., Chen, J.C. and Chuang, H.W. (2014) Impacts of size and shape of silver nanoparticles on Arabidopsis plant growth and gene expression. Plant Physiol. Biochem. 83, 57-64.

Taran, N., Storozhenko, V., Svietlova, N., Batsmanova, L., Shvartau, V. and Kovalenko, M. (2017) Effect of zinc and copper nanoparticles on drought resistance of wheat seedlings. Nanoscale Res. Let. 12, 1-6.

Van Kooten, O. and Snel, J.F.H. (1990) The use of chlorophyll fluorescence nomenclature in plant stress physiology. Photosyn. Res. 25, 147-150. 
Vannini, C., Domingo, G., Onelli, E., Prinsi, B., Marsoni, M., Espen L. and Bracale, M. (2013) Morphological and proteomic responses of Eruca sativa exposed to silver nanoparticles or silver nitrate. PLoS One, 8 , e6875.

Wellburn, A.R. (1994) The spectral determination of chlorophylls a and b, as well as total Carotenoids, using various solvents with spectrophotometers of different resolution. J. Plant Physiol. 144(3), 307-313.

Yamane, K., Kawasaki, M., Taniguchi, M. and Hiroshi, M.H. (2008) Correlation between chloroplast ultrastructure and chlorophyll fluorescence characteristics in the leaves of rice (Oryza sativa L.) grown under salinity. Plant Prod. Sci. 11, 139-145.

Younis, M.E., El-Shahaby, O.A., Nematalla, M.M. and El-Basrawisy, Z.M. (2003) Kinetin alleviates the influence of waterlogging and salinity on growth and affects the production of plant growth regulators in Vigna sinensis and Zea mays. Agron. 23, 277-285.

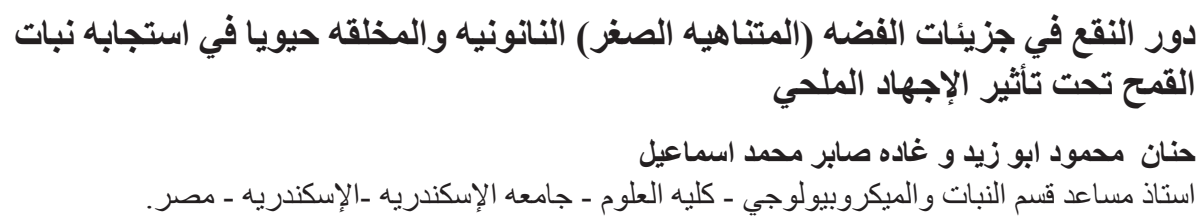

حُضرت جزيئات النانو لعنصر الفضه باستخدام المستخلص المائي لنبات الكبر (كاباريس سبينوسا) كعامل

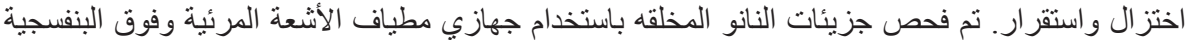

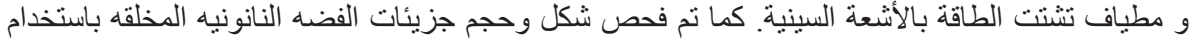

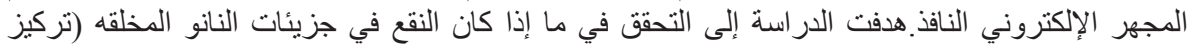

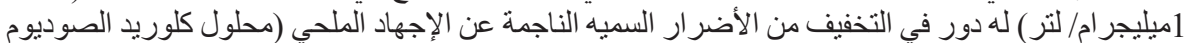

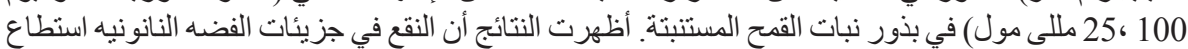

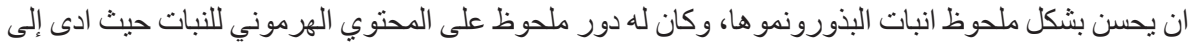

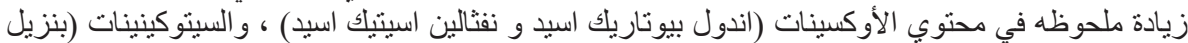

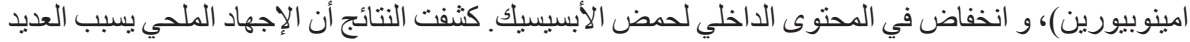

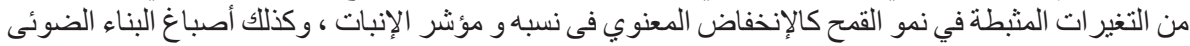

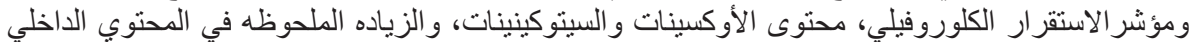

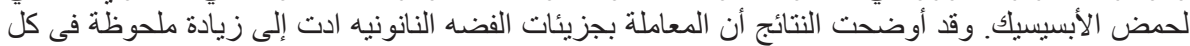

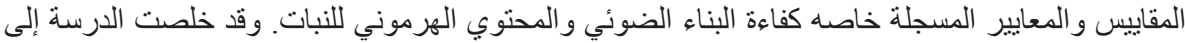
بيان دور النقع في جزيئات الفضه النانونيه في التخفيف من الأضر ار النئ الناجمة عن الإجهادات البيئيه مثل الإجهاد الملحى في نبات القمح. 